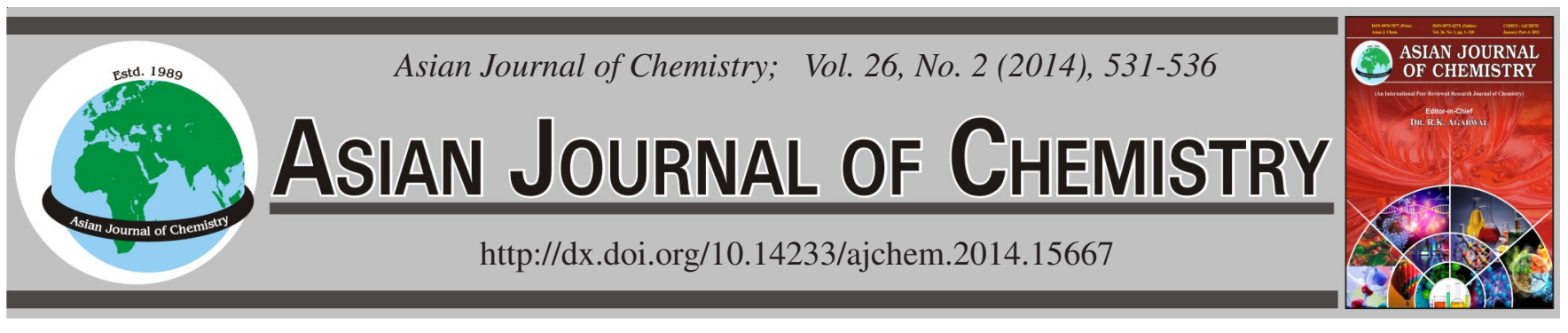

\title{
Antimicrobial Activity of Extract and Fractions of Different Parts and GC-MS Profiling of Essential Oil of Cichorium intybus Extracted by Super Critical Fluid Extraction
}

\author{
Muhammad Afzal $^{1}$, Muhammad Shahid $^{1, *}$, Zahid Mehmood $^{1}$, Shazia Anwer Bukhari $^{2}$ and Mir Munsif Ali Talpur ${ }^{3}$
}

${ }^{1}$ Department of Chemistry \& Biochemistry, University of Agriculture Faisalabad-38040, Pakistan

${ }^{2}$ Department of Applied Chemistry and Biochemistry, Government College University, Faisalabad, Pakistan

${ }^{3}$ Department of Chemistry, Shah Abdul Latif University, Khairpur, Sindh, Pakistan

*Corresponding author: Tel: +92 333 6629271; E-mail: mshahiduaf@yahoo.com

Received: 22 April 2013;

Accepted: 27 August 2013;

Published online: 15 January 2014;

AJC-14581

\begin{abstract}
Present study was conducted to appraise the antimicrobial potential of organic extracts of different parts of plant. Cichorium intybus widely known for their antimicrobial potential was used in the present investigation. Dry root, stem and leaves of medicinal plant was grounded to fine powder and extracted in methanol for 20 days. After this, methanol was allowed to evaporate and resulting residue was dissolved in different sequential solvents viz., hexane, ethyl acetate, $n$-butanol and water. Fraction of different organic solvents were used for antimicrobial activity. Essential oil of whole plant was extracted using supercritical fluid extraction method. Chemical profiling of essential oil was determined using GC-MS analysis. It is evident from the results of GC-MS analysis that essential oil of medicinal plant contains biological active organic compounds. Essential oil was also used against different bacterial and fungal strains that exhibited conspicuous antimicrobial activity. selected microorganisms Aspergillus niger, Fusarium solnai, Staphylococcus aureus and Escherichia coli were tested with activity $(20 \pm 1,20 \pm 0.6,22 \pm 0.4$ and $24 \pm 0.2$, respectively). Major constituents of essential oil determined by GC-MS analysis were tetratriacontane (21.58 \%), tetracosane (11.27\%), hexatriacontane (10.19\%), 9-octadecenoic acid, 1,2,3-propanetriyl ester, (E,E,E)- $(8.02 \%)$ and heneicosane $(7.03 \%)$. Antimicrobial potential of essential oil could have been due to these major constituents.
\end{abstract}

Keywords: Cichorium intybus, Antibacterial activity, GC-MS analysis, Medicinal plant, Antimicrobial activity.

\section{INTRODUCTION}

Chicory (Cichorium intybus L.) has historically been grown worldwide and this plant has medicinal uses. It was used in the folk medicine of ancient. In Pakistan, this plant is widely grown and it has been used as a leafy vegetable ${ }^{1}$, bioactive forage ${ }^{2}$. In recent years, a large number of medicinal functions of chicory have been researched. The extracts have also been known to reduce the level of lipids have hepatoprotective potential ${ }^{3}$. Chicory has been validated to exhibit antibacterial $^{4}$ and antifungal activity ${ }^{5}$. Furthermore, chicory is used as anti-inflammatory agents. Moreover, chicory extracts are commonly observed as safe by the Food and Drug Administration (FDA) ${ }^{6}$.

Cichorium intybus is a potential source of alkaloids, flavonoids, triterpenoids, tannins, saponins, fatty acids, volatile oils that make it suitable for use in medicines ${ }^{7}$. The volatile component contains octane, $n$-nanodecane, pentadecanone, hexadecane and penta salicylate ${ }^{8}$. The pharmacological studies indicated that chicory holds anticarcinogenic ${ }^{9}$. Chicory roots have been in use as a digestive aid, diuretic, laxative and slight sedative $^{10}$.
Phenolics have also been found to be natural antimicrobial mixtures, which are vital for snowballing the shelf life of food and inhibiting the growth of pathogenic microorganisms ${ }^{11}$. Chicory has been shown to possess substantial levels of phenolics that could be utilized for medicinal purposes ${ }^{12}$. The antifungal activity of chicory was also reported. The roots and leaves of this plant possess strong antibacterial and nematicidal effect. Many foods are recommended by physicians meant at enhancing ingestions of antioxidants so as to decrease the risk of chronic and degenerative disease linked to oxidative stress. The further importance is to need the study of different organic fractions of this plant to draw complete picture of its potential as antimicrobial activity. In addition, essential oil of chicory is also known to possess antifungal and antibacterial activity. However, validation of essential oil as antimicrobial agent requires GC-MS analysis which would highlight the compounds likely to be involved in antimicrobial activity. Supercritical fluid extraction is widely used now a days for extraction of oils state of art technique ${ }^{13}$. Previously various authors have evaluated biological properties of various plants of Pakistan ${ }^{14-21}$. More work is needed for the unexplored plants. It is already 
reported in the literature that the major component essential oil of the leaves ${ }^{22}$ of Mentha pulegium was piperitone (35.56\%), other predominant constituents were: piperitenone $(21.18 \%)$, $\alpha$-terpineol (10.89\%), pulegone (6.452\%), piperitone oxide (4.02\%), menthol (3.28\%), menthone (3.09\%), neomenthol $(2.80 \%)$, menthofuran $(2.15 \%)$, isomenthone $(1.56 \%)$, carvone $(1.13 \%)$, geranyl acetate $(1.06 \%)$, germacrene D $(1.03 \%)$ and limonene $(1.02 \%)$. In another study, the leaves and rhizomes of five Aframomum species, namely A. elliotii, A. strobilaceum, A. geocarpum, A. longiscarpum and A. sceptrum were subjected for hydrodistillation carried out with Clevenger apparatus type. Higher yields were found in the leaves varying between $0.28 \%$ and $0.42 \%$, while the rhizome oil shown lower yields accounting for $0.13-0.19 \%$. The results of the analysis of volatile oils by GC and GC/MS have showed 52 identified components with the total proportion ranged from 96.3 to $97.9 \%$. The chemical composition of the leaves oil was dominated by hydrocarbon compounds such as pinene, caryophyllene, humulene, selinene, selinene and germacrene A. Mean while, the rhizomes oil characterized with oxygenated components, namely eucalyptol, linalool and caryophyllene oxide accompanied by a few hydrocarbon constituents ${ }^{23}$. Likewise, the content of essential oil of Thymus comosus was assessed and the chemical composition of the essential oil was analyzed by gas-chromatography coupled with mass spectrometry. A content of 0.09-0.1\% essential oil was established. The main compounds identified in $T$. comosus essential oil were: caryophyllene-oxide (54.82\%), camphene (10.73\%), $\beta$-bourbonene $(5.90 \%)$, eudesmol (3.65\%), $\alpha$-pinene $(3.67 \%)^{24}$. Antimicrobial potential of this plant has been studied in India and other Asian countries. However, its activity has not been widely reported in Pakistan. Therefore, our aim was to report antimicrobial potential of chicory native in Pakistan. Furthermore, we were also interested to know chemical profile of the selected medicinal plants.

\section{EXPERIMENTAL}

Cichorium intybus plants were grown in Botanical garden, Department of Botany, University of Agriculture, Faisalabad, Pakistan. Plants were grown under natural conditions. The climate condition at the experimental site during the determination of different physiological attributes like day and night temperature was $39.28 \pm 3{ }^{\circ} \mathrm{C}$ and $22.92 \pm 4{ }^{\circ} \mathrm{C}$, respectively. photosynthetically available radiation (PAR) measured at non varied from 897 to $1364 \mu \mathrm{mol} \mathrm{m} \mathrm{m}^{-2} \mathrm{~s}^{-1}$ and day night RH 33.1/ $55.1 \%$, respectively while geographical location of New Botanical Garden was latitude $30^{\circ} .30 \mathrm{~N}$ and longitude $73^{\circ} .10 \mathrm{E}$ and altitude 213 from sea level. Plants at reproductive stage were harvested and shade dry material of this plant was used for antimicrobial activity.

Organic extraction: The shade-dried roots, stems and leaves were crushed and extracted with methanol at room temperature. The extract was evaporated in rotary evaporator to yield the residue. The whole residue was fractioned with $n$-hexane, chloroform, ethyl acetate, $n$-butanol and water ${ }^{25,26}$.

Separation of extract by flash chromatography: Flash chromatography is one of the useful techniques for separating mixture of organic compounds into pure components. It was performed by using a column with dimension $60 \mathrm{~cm}$ in length and $3 \mathrm{~cm}$ in diameter packed with silica gel 60 (230-400 mesh) purchased from Aldrich Sigma chemical company. The Cichoricum intybus extracts were loaded into the column as a solid mixture with some silica, which was prepared by suspending the mixture of about $5 \mathrm{~g}$ silica gel and $20 \mathrm{~mL}$ ethyl acetate, then ethyl acetate was removed under vacuum using rotary evaporator. The separation was started with pure hexane (low polarity) then the mobile phase polarity was increased gradually as follows: pure hexane, chloroform, ethyl acetate, $n$-butanol and distilled water ${ }^{27,28}$.

Extraction of essential oil by using supercritical fluid extraction (SCFE): The extraction procedure was followed by Cossuta et al. $^{29}$. In the super critical fluid extraction (SCFE) process extraction was carried out by a solvent above its critical pressure and temperature. Carbon dioxide was used as extraction solvent and this process was carried out at 100 bar pressure and temperature $40{ }^{\circ} \mathrm{C}$ at Institute of Horticultural Sciences, University of Agriculture, Faisalabad, Pakistan. The system used was (Deven Supercriticals Pvt. Ltd, Model No. PR-35).

Antimicrobial potential of the essential oil against micro organisms was performed by using standard dics diffusion method.

GC-MS analysis of essential oil: The sample was analyzed using a GC 6850 network GC system equipped with a 7683B series auto injector and 5973 inert mass selective detector (Agilent Technologies, Willmington, DE, USA). Compounds were separated on an HP-5 MS capillary column with a $5 \%$ phenyl polysiloxane stationary phase $(30.0 \mathrm{~m} \times$ $0.25 \mathrm{~mm}$, film thickness $0.25 \mu \mathrm{m}$ ). Oven temperature was programmed in a three step gradient: initial temp set at $45^{\circ} \mathrm{C}$ (held for $5 \mathrm{~min}$ ), ramped till $150{ }^{\circ} \mathrm{C}$ at $10^{\circ} \mathrm{C} / \mathrm{min}$, followed by a $5^{\circ} \mathrm{C} / \mathrm{min}$ rise till $280^{\circ} \mathrm{C}$ and finally at $15^{\circ} \mathrm{C} / \mathrm{min}$ to $325^{\circ} \mathrm{C}$ where it was held for $5 \mathrm{~min}$. Helium gas flow rate was $1.1 \mathrm{~mL} / \mathrm{min}$ (pressure $60 \mathrm{KP}_{\alpha}$ and linear velocity $38.2 \mathrm{~cm} / \mathrm{sec}$ ). Ions/fragments were monitored in scanning mode through $40-550 \mathrm{~m} / \mathrm{z}$.

Identification of compounds: The identification of the components was based on comparison of their retention index (RI), relative to a standard alkane series (C9-C24). The compounds were further identified and authenticated using their MS data by comparison with those of the NIST 05 Mass Spectral Library and published mass spectra. The quantitative data were obtained electronically from the FID area percentage without the use of any correction factors ${ }^{25}$.

Antimicrobial assay by disc diffusion method: Nutrient agar (Oxoid,UK) was prepared, medium heated mixed and then autoclaved. Before transferring this medium in sterilized Petri plates, $100 \mathrm{~mL}$ inoculum was added in medium while it was liquid and quite cool. Mixed and then pour into Petri plates. After this, $6 \mathrm{~mm}$ Wicks paper discs were laid flat on growth medium and $100 \mu \mathrm{L}$ of extract was put on each disc. The Petri plates were then incubated at $37^{\circ} \mathrm{C}$ for $24 \mathrm{~h}$, for the growth of bacteria. The extracts having antibacterial activity, inhibited the bacterial growth and clear zone of inhibition was formed. The zones of inhibition were measured in millimeters using zone reader ${ }^{28}$ and for fungal growth PDA (Oxoid, UK) was used. Antifungal activity of sample against selected fungal strains was determined by using disc diffusion method ${ }^{30}$.

Fungal and bacterial strain and standard used: Fungal strains used were Fusarium solani, Aspergillus niger, Tricho- 
derma harzianum and Helmmentho sporiummyedis, species and bacterial strains were Escherichia coli, Pasturella multocida, Staphylococcus aureus and Bacillus subtilis, etc. were used for the assay. The fungal and bacterial strains were maintained on Potato Dextrose Agar (PDA) oxoid, UK and nutrient agar (oxoid, UK) respectively ${ }^{31}$.

Minimum inhibitory concentration (MIC): Minimum inhibitory concentration of different collected samples was determined by micro dilution methods on the selected fungal and bacterial strains ${ }^{32}$.

Statistical analysis: The collected data was presented in the tabulation form. To find the optimum antimicrobial potential regression analysis was performed. the statistical software STATISTICX version (stat soft, tulsa Okahoma,USA) was used for statistic analysis

\section{RESULTS AND DISCUSSION}

Chloroform leaf extract of Cichorium intybus possessed strong activity $(22 \pm 0.25 \mathrm{~mm})$ against Tricoderma harzianum and also ethyl acetate stem extraction have strong activity (21 $\pm 0.23 \mathrm{~mm}$ ) but Chichorium intybus root extraction in different solvents showed moderately strong antimicrobial activity because their cells are metabolically more active than stem and root cells. There are different studies in the literature that depicted the antimicrobial potential of different parts of Chichorium intybus extracted in different solvents (Table-1). Table-1 showed that water extraction of leaf and stem and ethyl acetate extraction of chicory root showed strong activity against F. solani. This study also showed that water extraction of leaf and $n$-butanol extraction of stem and root showed strong activity against $H$. sporiummyedis. It is clear from the above results that water and $n$-butanol extraction of leaf showed strong activity while other extraction of stem and root showed moderate activity against Aspergillus niger and also the minimum inhibitory concentration (MIC) value of ethyl acetate against selected fungal strain were in range of $18.5 \pm 0.06$ to $156 \pm 0.05 \mathrm{~mm}$.

Natural compounds with antifungal activity for medicinal plants have been abundantly reported. Roots of the common medicinal plant Cichorium intybus L., highly appreciated for its bitter taste, were studied to investigate their possible biological activity on fungi from a variety of ecological environments. Some are parasites on plants (phytopathogens) or on animals and humans (zoophilic and anthropophilic dermatophytes), others live on the soil and only seldom parasitize animals (geophilic dermatophytes). The extracts were ineffective on geophilic species and on tested phytopathogens, with the exception of Pythium ultimum. This behaviour is discussed on the basis of presence in the chicory extract of the two main sesquiterpene lactones, 8-deoxylactucin and 11b, 13-dihydrolactucin ${ }^{33}$. There are several reports in the literature that depict the antimicrobial potential of different parts of Chichorium intybus extracted in different organic solvents. In this context ${ }^{34}$, reported antimicrobial activity of ethyl acetate, water and ethanol extracts against Agrobacterium radiobacter sp. tumefaciens, Erwinia carotovora, Pseudomonas fluorescens and $P$. aeruginosa. In our investigation, ethyl acetate extract was found to be very effective.

Chichorium intybus leaf extract prepared in chloroform showed good results $(26 \pm 0.3)$ against selected bacterial strain S. aureus. Root extract also showed strong activity but stem extract in different solvent showed moderate activity. Results in Table-2. have shown that Chichorium intybus stem extract prepared in ethyl acetate showed good results with value (20 \pm 0.20 ) against $B$. subtilis. Root and leaf extract showed moderate activity. Present study also revealed that the Chichorium intybus stem, leaf and root extracts prepared in $n$-butanol showed good results against $E$. coli. Results in the above table have shown that the Chichorium intybus leaf and root extracts prepared in $n$-butanol showed good results against selected bacterial strain $P$. multocida stem extract showed moderate activity and also the minimum inhibitory concentration (MIC) value of ethyl acetate and chloroform were in range of $22.5 \pm$ 0.02 to $179 \pm 0.04 \mathrm{mg} / \mathrm{mL}$.

There are number of reports that indicated the antimicrobial potential of organic extracts of different plants parts of Cichorium intybus. In this context, Nandagopal and Ranjitha ${ }^{35}$ extracted organic compounds from roots of Chichorium intybus

TABLE-1

ANTIFUNGAL ACTIVITY IN TERMS OF ZONE OF INHIBITION (mm) BY Chichorium intybus AGAINST SELECTED FUNGAL STRAINS

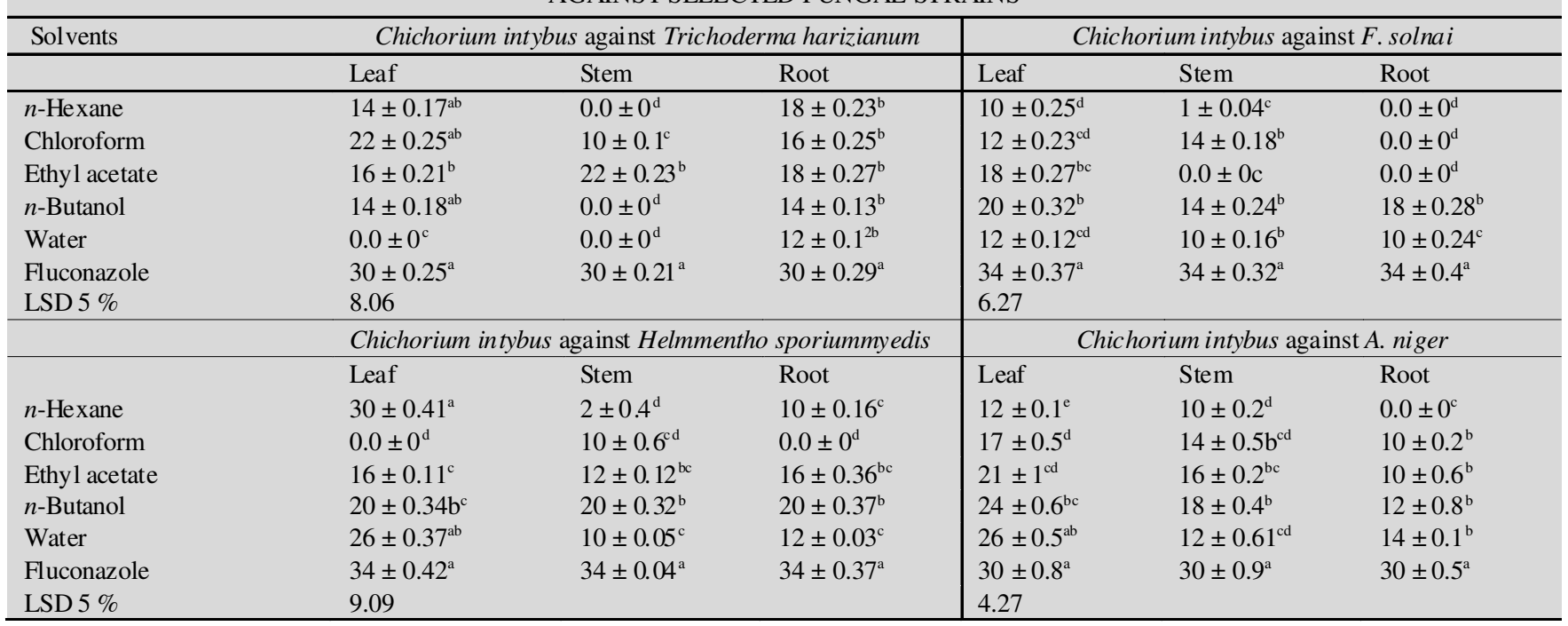


TABLE-2

ANTIBACTERIAL ACTIVITY OF Chichorium intybus SAMPLES AGAINST SELECTED BACTERIAL STRAINS

\begin{tabular}{|c|c|c|c|c|c|c|}
\hline \multirow[t]{2}{*}{ Solvents } & \multicolumn{3}{|c|}{ Chichorium intybus against $S$. aureus } & \multicolumn{3}{|c|}{ Chichorium intybus against $B$. subtilis } \\
\hline & Leaf & Stem & Root & Leaf & Stem & Root \\
\hline$n$-Hexane & $16 \pm 0.2^{c}$ & $10 \pm 0.4^{b}$ & $10 \pm 0.1^{\mathrm{c}}$ & $10 \pm 0.42^{b}$ & $10 \pm 0.17^{\mathrm{d}}$ & $0.0 \pm 0^{\mathrm{d}}$ \\
\hline Chloroform & $26 \pm 0.3^{b}$ & $10 \pm 0.5^{b}$ & $20 \pm 1^{b}$ & $12 \pm 0.21^{\mathrm{b}}$ & $12 \pm 0.16^{\mathrm{cd}}$ & $12 \pm 0.33^{c}$ \\
\hline Ethyl ace tate & $18 \pm 0.5^{\mathrm{c}}$ & $12 \pm 0.2^{b}$ & $20 \pm 0.9^{b}$ & $10 \pm 0.47^{\mathrm{b}}$ & $20 \pm 0.20^{\mathrm{b}}$ & $14 \pm 0.32^{\mathrm{bc}}$ \\
\hline$n$-Butanol & $16 \pm 0.1^{\mathrm{c}}$ & $14 \pm 0.7^{b}$ & $24 \pm 0.5^{b}$ & $12 \pm 0.17^{\mathrm{b}}$ & $18 \pm 0.22^{b}$ & $16 \pm 0.29^{\mathrm{bc}}$ \\
\hline Water & $10 \pm 0.4^{\mathrm{d}}$ & $0.0 \pm 0^{\mathrm{c}}$ & $14 \pm 0.3^{c}$ & $14 \pm 0.18^{b}$ & $16 \pm 0.28^{b c}$ & $18 \pm 0.24^{\mathrm{b}}$ \\
\hline Rifamycin & $36 \pm 0.3^{\mathrm{a}}$ & $36 \pm 0.6^{\mathrm{a}}$ & $36 \pm 0.5^{\mathrm{a}}$ & $36 \pm 0.21^{\mathrm{a}}$ & $36 \pm 0.31^{\mathrm{a}}$ & $30 \pm 0.23^{\mathrm{a}}$ \\
\hline \multirow[t]{2}{*}{ LSD $5 \%$} & 5.18 & & & 4.19 & & \\
\hline & \multicolumn{3}{|c|}{ Chichorium intybus against $E$. coli } & \multicolumn{3}{|c|}{ Chichorium intybus against $P$. multocida } \\
\hline & Leaf & Stem & Root & Leaf & Stem & Root \\
\hline$n$-Hexane & $20 \pm 0.41^{\mathrm{b}}$ & $8 \pm 0.32^{d}$ & $12 \pm 0.2^{c}$ & $16 \pm 0.6^{\mathrm{c}}$ & $12 \pm 0.07^{\mathrm{c}}$ & $10 \pm 0.04^{\mathrm{c}}$ \\
\hline Chloroform & $10 \pm 0.11^{\mathrm{c}}$ & $12 \pm 0 c^{d}$ & $16 \pm 0.7^{\mathrm{bc}}$ & $20 \pm 0.12^{b}$ & $12 \pm 0.08^{c}$ & $12 \pm 0.06^{\mathrm{c}}$ \\
\hline Ethyl ace tate & $12 \pm 0.34^{\mathrm{c}}$ & $16 \pm 0.29^{\mathrm{bc}}$ & $20 \pm 0.31^{\mathrm{b}}$ & $14 \pm 0.06^{\mathrm{c}}$ & $18 \pm 0.015^{\mathrm{b}}$ & $16 \pm 0.08^{b}$ \\
\hline$n$-Butanol & $20 \pm 0.23^{b}$ & $20 \pm 0.6^{b}$ & $28 \pm 0.1^{\mathrm{a}}$ & $20 \pm 0.06^{\mathrm{b}}$ & $16 \pm 0.13^{b}$ & $20 \pm 0.06^{\mathrm{b}}$ \\
\hline Rifamycin & $34 \pm 0.34^{\mathrm{a}}$ & $34 \pm 0.12^{\mathrm{a}}$ & $34 \pm 0.11^{\mathrm{a}}$ & $36 \pm 0.15^{a}$ & $36 \pm 0.06^{\mathrm{a}}$ & $36 \pm 0.06^{\mathrm{a}}$ \\
\hline LSD $5 \%$ & 6.40 & & & 3.22 & & \\
\hline
\end{tabular}

plants with different organic solvent including ethyl acetate, chloroform and $n$-hexane. These authors further studied the antimicrobial activity of the organic extracts against E. coli, B. subtilis and $S$. aureus. The organic extract of ethyle acetate exhibited $13.6 \pm 0.29 \mathrm{~mm}$ antibacterial activity against $E$. coli, whereas chloroform and $n$-hexane extracts showed (14.0 \pm $0.31 \mathrm{~mm}$ and $12.3 \pm 0.21 \mathrm{~mm}$ ), aganist Bacillus subtilis, S. aureus, respectively. Likewise, water, ethanol and ethyl acetate extracts of chicory exhibited marked antibacterial activity against Agrobacterium radiobacter, Erwinia carotovora, Pseudomonas fluorescens and Pseudomonas aeruginosa with inhibition zone $(21.7,20.5,20.0,20,0 \mathrm{~mm})$, respectively ${ }^{34}$. Sheikh and coworkers ${ }^{36}$ reported the similar results by using organic and water extracts of cichory seeds against $S$. aureus, Pseudomonas aeruginosa, Candida albicans and E. coli. All the seed extracts showed antimicrobial activity against selected microorganisms whereas $S$. aureus was found to be the most sensitive against aqueous extract and had the widest zone of inhibition. Ethyl acetate and ethanol extract were found to be significant against $P$. aeruginosa and $S$. aureus. Seed extract of Chichorium intybus was found to be very effective antimicrobial against Staphylococcus aureus, Pseudomonas aeruginosa, Candida albicans and Escherichia coli. From the extract and various fractions, ethyl acetate and ethanol were observed the most effective one ${ }^{36}$ (Tables 1 and 2).

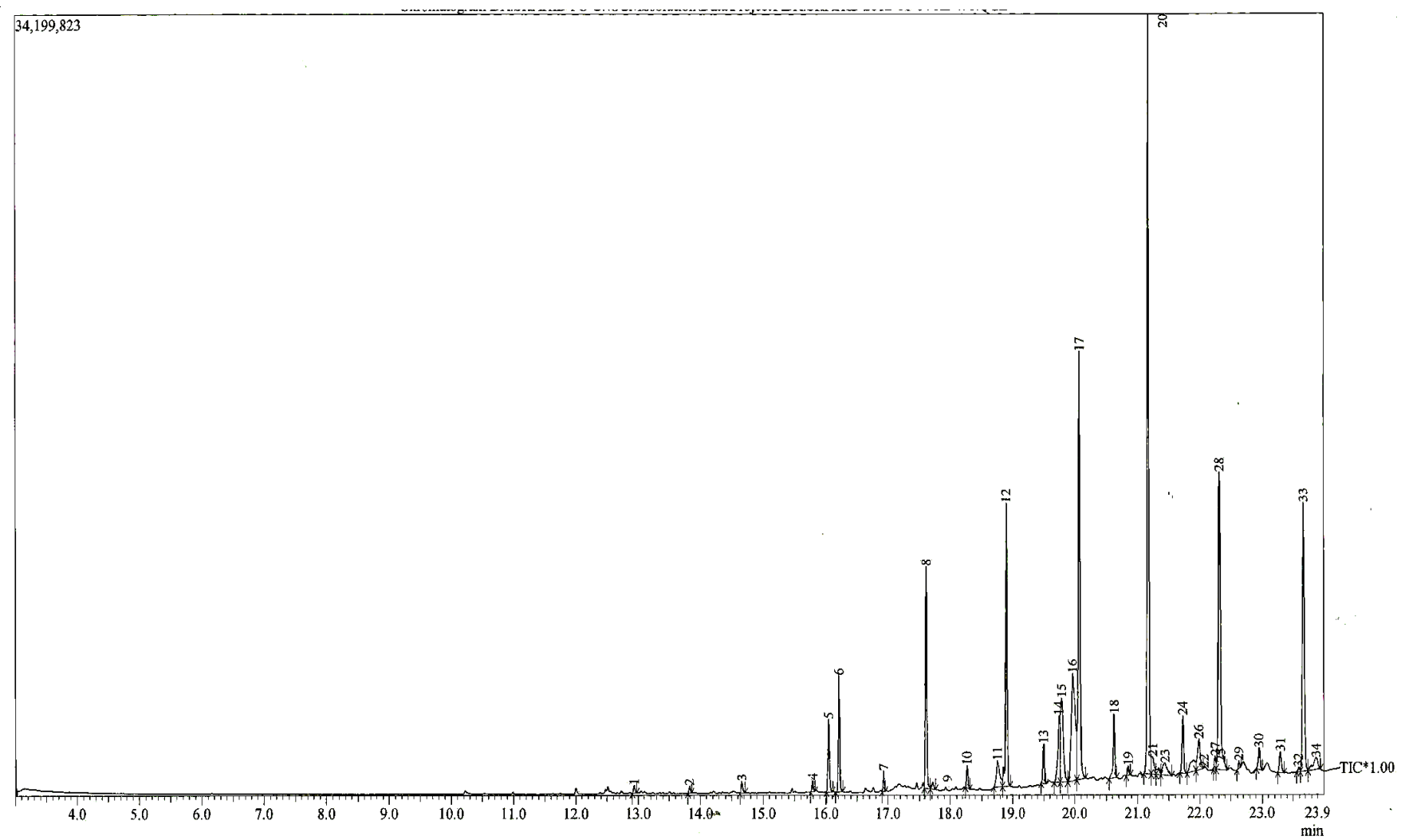

Fig. 1. GC-MS analysis of essential oil of Cichorium intybus obtained using supercritical fluid extraction methods 
Table-3 (Fig. 1) showed GC-MS analysis of essential oil from Chichorium intybus plant extract by using super critical fluid extraction system. Extract enabled the identification of 30 components, representing of the total fraction (99.01\%). This volatile fraction consisted of a mixture of different classes of compounds. The major constituents were found to be tetratriacontane $(21.58 \%)$, tetracosane $(11.27 \%)$, hexatriacontane $(10.19 \%)$, 9-octadecenoic acid, 1,2,3-propanetriyl ester, (E, E,E)- $(8.02 \%)$ and heneicosane $(7.03 \%)$. Mehmood and coworker ${ }^{37}$ reported the chemical composition of a lipophilic extract of Chichorium intybus. Most of $n$-alkanes and fatty acids components were recognized.

Microbial strains: The antimicrobial activity was evaluated by paper disc diffusion methods. The qualitative antimicrobial activity was carried out by the disc diffusion against four selected microbial strain: E. coli, S. aureus, A. niger and $F$. solani by using the method of Riaz et al. ${ }^{26}$.

Table-4 showed antimicrobial activities of Cichorium intybus was positive against selected fungal and bacterial strain. The antimicrobial activity might be due to following compounds tetratriacontane $(21.58 \%)$, tetracosane $(11.27 \%)$, hexatriacontane $(10.19 \%)$, octadecenoic acid, 1,2,3-propanetriyl ester, (E,E,E)-(8.02\%) and heneicosane (14.64\%). There are a number of reports available in the literature that depicted the antimicrobial activity of chemicals found in essential oil of medicinal plants, e.g., essential oil of Thymus vulgaris, Thymus serphyllum, Saliva officinalis and Pimpinella anisum ${ }^{38}$ reported the antimicrobial activity of essential oil of Lavandula multifida against Gram-negative and Gram positive pathogenic bacteria. It observed that essential oil of aromatic medicinal plants had significant antimicrobial potential ${ }^{39}$. It was recorded the antimicrobial potential of essential oil of Coriandrum sativum against S. aureus, Enterobacter aerogenes, Klebsiella pneumonia, Vibrio cholera and Salmonella typhi ${ }^{40}$.

\section{Conclusion}

The Cichorium intybus plant extracts possessed substantial antimicrobial activity. This antimicrobial activity might have been due to the presence of biologically important phytoconstituents in different plant extracts. In addition, GC-MS analysis of essential oil of this plant exhibited the presence of 34 phytochemicals widely known for their biological activities. The most active compounds known to possess antimicrobial potential should be further characterized for their use as medicines. This is extremely important as bacteria are getting resistant to a wide range of antibiotics used to cure bacterial diseases in humans.

\section{ACKNOWLEDGEMENTS}

The authors are highly thankful to the Higher Education Commission Islamabad, Pakistan for providing funds (HEC Indigenous Scholarship) for the purchase of chemicals and other research-related materials.

TABLE-3

CHEMICAL COMPOSITION ANALYSIS OF ESSENTIAL OIL FROM WHOLE PLANT OF Chichorium intybus BY GC-MS OBTAINED BY SUPER CRITICAL FLUID EXTRACTION (SCFE)

\begin{tabular}{|c|c|c|c|}
\hline Sr. No & Retention Time & Compound Name & Area $\%$ \\
\hline 1 & 12.938 & Tetradecane & 0.18 \\
\hline 2 & 13.825 & Hexadecane & 0.16 \\
\hline 3 & 14.661 & Heptadecane & 0.31 \\
\hline 4 & 15.791 & $6,10,14$-Trimethyl pentasdecanone, & 0.25 \\
\hline 5 & 16.042 & Z-5-Nonadecene & 1.67 \\
\hline 6 & 17.615 & Heneicosane & 14.64 \\
\hline 7 & 17.714 & Phytol & 0.26 \\
\hline 8 & 18.752 & 1,30 -Triacontanediol & 1.58 \\
\hline 9 & 19.497 & Tetracosane & 0.95 \\
\hline 10 & 19.742 & Hentertracontanol & 2.64 \\
\hline 11 & 17.786 & Tritriacontane & 3.14 \\
\hline 12 & 17.967 & (E,E,E)-1,2,3-Propanetriyl 9-octadecenoic acid ester & 8.02 \\
\hline 13 & 20.075 & Tetracosane & 11.27 \\
\hline 14 & 20.628 & Tetratriacontane & 1.83 \\
\hline 16 & 21.173 & Tetratriacontane & 21.58 \\
\hline 17 & 21.242 & 3,7-Dimethyl1-6-octenyl butanoic acid ester & 0.77 \\
\hline 18 & 21.342 & Methyl tetraconsanoic acid ester & 0.35 \\
\hline 19 & 21.437 & Lup-20(29)-en-3-one & 0.98 \\
\hline 20 & 21.720 & Hexatriacontane & 1.61 \\
\hline 21 & 21.850 & Lupeol & 1.04 \\
\hline 22 & 21.982 & Oxirane, heptadecyl & 1.47 \\
\hline 23 & 22.239 & 1-(1-tetradecylpentadecyl)cyclohexane & 0.36 \\
\hline 24 & 22.312 & Hexatriacontane & 10.19 \\
\hline 25 & 22.627 & 1-Ethenyl-1,5-dimethyl-4-hexenyl octanoic acid ester & 0.20 \\
\hline 26 & 22.950 & Hexatriacontane & 0.65 \\
\hline 27 & 23.293 & Heptadecyl-oxirane & 0.70 \\
\hline 28 & 23.583 & (Z,Z)-9,9-hexadecenyl hexadecenoic acid ester & 0.17 \\
\hline 29 & 23.671 & Hexatriacontane & 9.78 \\
\hline
\end{tabular}


TABLE-4

ANTIMICROBIAL ACTIVITY OF ESSENTIAL OIL OF Cichorium intybus

\begin{tabular}{lcccc}
\hline Essential oil & Aspergillus niger & Fusarium solnai & Staphylococcus aureus & Escherichia coli \\
C. intybus & $20 \pm 1$ & $20 \pm 0.6$ & C. intybus & $22 \pm 0.4$ \\
Fluconazole & $30 \pm 0.9$ & $28 \pm 0.7$ & Rifamycin & $26 \pm 0.2$ \\
\hline
\end{tabular}

\section{REFERENCES}

1. V. Mulabagal, H. Wang, M. Ngouajio and M.G. Nair, Eur. Food Res. Technol., 230, 47 (2009).

2. N. Noor, R.A. Sarfraz, S. Ali and M. Shahid, Food Chem., 143, 362 (2014).

3. A. Hassan, S. Rahman, F. Deeba and S. Mahmud, J. Med. Plants Res., 3, 20 (2009).

4. N. Mehmood, M. Zubair, K. Rizwan, N. Rasool, M. Shahid and V.U. Ahmad, Iran. J. Pharm. Res., 11, 1145 (2012).

5. M. Riaz, N. Rasool, I.H. Bukhari, M. Zubair, M. Shahid, T.H. Bokhari, Y. Gull, K. Rizwan, M. Iqbal and M. Zia-ul-Haq, Oxid. Commun., 36, 542 (2013).

6. B.M. Schmidt, N. Ilic, A. Poulev and I. Raskin, Food Chem. Toxicol., 45, 1131 (2007).

7. P. Nandagopal and B. Ranjitha, Adv. Biol. Res., 1, 17 (2007).

8. A. Judzentiene and J. Budiene, Chemija, 19, 25 (2008).

9. B. Hazra, R. Sarkar, S. Bhattacharyya and P. Roy, Fitoterapia, 73, 730 (2002).

10. J.H. Kim, E.J. Lee, D.O. Shin, S.E. Hong and J.K. Kim, J. Korean Assoc. for Radiat. Prot., 25, 37 (2000).

11. P.M. Davidson and A.L. Branen, J. Food Prot., 44, 623 (1981).

12. T.A. Bischoff, C.J. Kelley, Y. Karchesy, M. Laurantos, P. Nguyen-Dinh and A.G. Arefi, J. Ethnopharmacol., 95, 455 (2004).

13. E. Reverchon, J. Supercritical Fluids, 10, 1 (1997).

14. E.M. Abdallah and A.E. Khalid, Int. J. Chem. Biochem. Sci., 1, 1 (2012).

15. S. Ahmad, M. Akhter, M. Zia-Ul-Haq, Mehjabeen and S. Ahmed, Pak. J. Bot., 42, 1327 (2010).

16. A.A. Hamid and O.O. Aiyelaagbe, Int. J. Chem. Biochem. Sci., 1, 99 (2012).

17. M.A. Hanif, M.Y. Al-Maskari, A. Al-Maskari, A. Al-Shukaili, A.Y. AlMaskari and J.N. Al-Sabahi, J. Med. Plants Res., 5, 751 (2011)

18. M. Lateef, L. Iqbal, N. Fatima, K. Siddiqui, N. Afza, M. Zia-ul-Haq and M. Ahmad, Pak. J. Pharm. Sci., 25, 99 (2012).

19. K. Rehman, S. Ashraf, U. Rashid, M. Ibrahim, S. Hina, T. Iftikhar and S. Ramzan, Pak. J. Bot., 45, 391 (2013).

20. Sobia, M. Zubair, N. Rasool, M. Asim, F. Anjum, M. Iqbal, M. Mushtaq and M. Shahid, J. Med. Plants Res., 7, 243 (2012).
21. M. Zia-ul-Haq, S. Ahmad, S. Iqbal, D.L. Luthria and R. Amarowicz, Oxid. Commun., 34, 820 (2011).

22. E. Derwich, Z. Benziane and R. Taouil, Chem. Bull. Politehnica Univ. Timisoara, Romania, 55, 103 (2010).

23. G.D. Diomande, A.M. Koffi, Z.F. Tonzibo, G. Bedi and G. Figueredo, Middle-East J. Sci. Res., 11, 808 (2012).

24. M. Pavel, V. Radulescu and D.C. Ilies, Farmacia, 57, 479 (2009).

25. M. Govindarajan, A. Jebanesan, D. Reetha, R. Amsath, T. Pushpanathan and K. Samidurai, Eur. Rev. Med. Pharmacol. Sci., 12, 299 (2008).

26. M. Riaz, N. Rasool, I.H. Bukhari, M. Shahid, M. Zubair, K. Rizwan and U. Rashid, Molecules, 17, 14275 (2012).

27. B. Moosmann, S. Kneisel, U. Girreser, V. Brecht, F. Westphal and V. Auwärter, Forensic Sci. Int., 220, e17 (2012).

28. M. Riaz, N. Rasool, I. Bukhari, M. Shahid, F. Zahoor, M. Gilani and M. Zubair, Afr. J. Microbiol. Res., 6, 5700 (2012).

29. D. Cossuta, B. Simandi, E. Vagi, J. Hohmann, A. Prechl, E. Lemberkovics, A. Kery and T. Keve, J. Supercrit. Fluids, 47, 188 (2008).

30. B. Mahesh and S. Satish, World J. Agric. Sci., 4, 839 (2008).

31. F. Anjum, M. Shahid, S.A. Bukhari, S. Anwar and S. Latif, J. Food Proc. Technol., 2, 4 (2013).

32. S.D. Sarker, L. Nahar and Y. Kumarasamy, Methods, 42, 321 (2007).

33. D. Mares, C.B. Romagnoli, B. Tosi and E. Andreotti, Fragrance, 13, 235 (2005)

34. J. Petrovic, A. Stanojkovic, L.J. Comic and S. Curcic, Fitoterapia, 75, 737 (2004).

35. P. Nandagopal and B. Ranjitha, Ad. Biol. Res., 1, 17 (2007).

36. T. Sheikh, R.A. Rub and S. Sasikumar, Arabian J. Chem., in press (2014).

37. N. Mehmood, M. Zubair, K. Rizwan, N. Rasool, M. Shahid and V. Ahmad, Iran. J. Pharm. Res., 11, 1145 (2012).

38. F. Benbelaid, M. Bendahou, A. Khadir, M.A. Abdoune, C. Bellahsene, F. Zenati, W. Bouali and D.E. Abdelouahid, J. Microbiol. Biotechnol. Res., 2, 244 (2012).

39. M. Vasinauskiene, J. Radusiene, I. Zitikaite and E. Surviliene, Agronomy Res., 4, 437 (2006).

40. S. Suganya, R. Bharathidasan, G. Senthilkumar, P. Madhanra and A. Panneerselvam, J. Chem. Pharm. Res., 4, 1846 (2012). 